\title{
Dinâmica populacional, uso da terra e geração de renda: uma análise longitudinal para domicílios rurais na Amazônia equatoriana
}

Alisson F. Barbieri

Departamento de Demografia e Cedeplar/UFMG

Richard E. Bilsborrow Department of Biostatistics and Carolina Population Center, University of North Carolina at Chapel Hill, USA

\section{Palauras-chave \\ Amazônia, Equador, população, renda, uso da terra.}

Classificação JEL Q12, R11, R14.

\footnotetext{
Key words

Amazon, Ecuador, population, income, land use.
}

JEL Classification Q12, R11, R14.

\section{Resumo}

A área em estudo neste artigo, no Norte da Amazônia equatoriana, é a principal região de colonização por migrantes no país desde os Anos 70, e tem experimentado grandes mudanças em anos recentes, incluindo rápido crescimento populacional e urbano, fragmentação de lotes rurais, mudanças nas formas de uso da terra, e aumento na oferta de trabalho assalariado fora dos lotes. Essas mudanças têm afetado de forma importante a renda e bem-estar dos colonos. Este artigo utiliza dados detalhados de uma pesquisa longitudinal de colonos migrantes em 1990 e 1991, para estimar a renda domiciliar gerada tanto a partir de atividades no próprio lote rural, quanto fora do lote. São estimados, ainda Coeficientes de Gini para a desigualdade na distribuição de terras e renda domiciliar, e avaliadas possíveis causas das mudanças na renda nos Anos 90. O artigo é finalizado com uma discussão sobre políticas que possam aliviar a pobreza e atingir um padrão de desenvolvimento mais sustentável.

\section{Abstract}

The Northern Ecuadorian Amazon, the principal region of colonization of migrants in Ecuador since the 1970's, has been experiencing major changes in recent years, including a rapidly growing population, fragmentation of agricultural plots, changes in land use, and increasing off-farm employment, all of which are affecting farm household incomes and well-being. In this paper we use detailed data from a longitudinal survey of migrant settlers in 1990 and 2000 in Ecuador to first estimate farm household incomes, on-farm and off-farm. We then compute Gini coefficients for both land distribution and household income, and evaluate factors responsible for changes in household income in the 1990s.

The article ends with a discussion of the policies that could reduce poverty and lead to a more sustainable standard of development. 


\section{1_Introdução}

As últimas três décadas têm sido marcadas pela retomada do processo de expansão das fronteiras agrícolas, particularmente em direção a florestas tropicais como a Amazônia. Vários estudos documentam a importância dessas regiões para o clima local, regional e global, incluindo suas funções como reguladoras das mudanças climáticas globais, com a conservação da biodiversidade, bem como suas funções de manutenção de ciclos hidrológicos (Myers, 1989; Shukla et al., 1990; Wilson, 1992; Adger e Brown, 1994; Brown, 1994; O’Brien, 1995; Fearnside, 1996; Tinker et al., 1996; Dale, 1997; Laurance e Williamson, 2001). Há ainda uma modesta, embora crescente, literatura que demonstra evidências sobre as relações críticas entre população e ambiente particularmente os efeitos da dinâmica demográfica e das atividades humanas sobre o uso da terra e o desmatamento em regiões de fronteira em várias regiões do mundo, especialmente na Amazônia (e.g., Panayoutou e Sungsuwan, 1994; Walker e Homma, 1996; Pichón, 1997; Rudel e Roper, 1997; Rosero-Bixby e Palloni, 1998; Perz, 2002; Walker et al., 2002; Carr, 2004; Barbieri et al., 2005a), e sobre os efeitos de tais dinâmicas acerca da saúde humana, particularmente a prevalên- cia e a incidência de malária (e.g., Singer e Sawyer, 1992; Barbieri et al., 2005b). Apesar da considerável atenção, na literatura, às implicações ambientais da extensividade da fronteira agrícola em regiões de florestas tropicais, pouca atenção tem sido dada às consequências desse processo para as próprias populações locais, que são, a rigor, tidas como protagonistas da destruição ambiental. Melhor compreensão dessas consequências é fundamental para pensar (ou repensar) políticas de desenvolvimento sustentável, em regiões como a Amazônia, que levem em consideração as aspirações e atividades econômicas das populações locais, particularmente as famílias de colonos migrantes.

Este artigo busca uma reflexão sobre as questões acima se valendo de evidências empíricas raras, relacionadas a uma fonte de dados longitudinal baseada em uma amostra representativa de colonos migrantes na Amazônia Ocidental, em uma área que compreende o Norte da Amazônia equatoriana. Este estudo de caso apresenta uma biodiversidade extraordinária (Myers, 1988; Myers et al., 2000) que tem sido sujeita às mais rápidas taxas de desmatamento entre todos os países amazônicos (FAO, 2005). O Norte da Amazônia equatoriana, região também conhecida como "Oriente", teve o processo de colonização por po- 
pulações não autóctones iniciado, em larga escala, a partir da descoberta de petróleo em 1967, nas proximidades da atual cidade de Lago Agrio.

Os dados longitudinais, que permitem uma análise da dinâmica populacional e de uso da terra e geração de renda das famílias de colonos, correspondem a uma coleta realizada em 1990, com o follow-up em 1999. Os resultados da análise de níveis e padrões de renda em 1990 foram descritos por Murphy (1998) e são resumidos neste artigo. Em seguida, esta análise é estendida de forma a incorporar, de forma inédita, os resultados da pesquisa realizada em 1999 e as mudanças ocorridas no tempo. $\mathrm{O}$ artigo também examina a associação entre renda e vários fatores como tamanho da propriedade rural, tamanho do domicílio e estratégias gerais de alocação de trabalho e terra por parte de domicílios rurais.

\section{2_Renda domiciliar rural em regióes de fronteira: estudos anteriores e aspectos conceituais}

A pesquisa empírica sobre renda e bemestar em áreas de fronteira tem sido, majoritariamente, relacionada à literatura em história econômica de processos de colonização na Inglaterra e nos Estados Uni- dos da América. A pesquisa contemporânea em países em desenvolvimento, embora mais limitada, tem em comum o fato de ser baseada quase que integralmente em dados incompletos sobre renda familiar, como, por exemplo, a qualidade da habitação e o acesso à eletricidade. Apesar do crescente interesse nos aspectos ambientais da expansão das fronteiras agrícolas em diversas partes da América Latina, da África e da Ásia, a carência de pesquisas tem sido relacionada à falta de fontes de dados apropriadas, as quais, por sua vez, requerem grande esforço de coleta, processamento e análise.

Diversos estudos têm investigado a situação econômica dos migrantes em áreas de fronteira na Bacia Amazônica, incluindo Henriques (1988), Schmink e Wood (1992) e Walker et al. (2002), sobre o Brasil; Aramburu (1984) e Loker (1993), sobre o Peru; Uquillas (1984) e Rudel e Horowitz (1993), sobre o Equador; e Painter (1987), sobre a Bolívia. Entretanto, nenhum desses estudos é baseado em informações detalhadas sobre renda domiciliar rural. Entre os poucos estudos sobre famílias de colonos migrantes em áreas de fronteira baseados em dados em nível micro ou dados de pesquisas domiciliares estão Almeida (1992), sobre a Amazônia brasileira, e Murphy et al. (1997), sobre a Amazônia equatoriana. Al- 
meida investigou níveis de renda, bem-estar e investimentos nas áreas rurais baseado em uma amostra de domicílios e concluiu que colonos assentados em projetos oficiais (patrocinados pelo governo federal) tendem a ter uma situação melhor, sendo que alguns apresentavam alta renda domiciliar, mas também grandes débitos acumulados ao longo do tempo. A maioria dos lotes e domicílios rurais na Amazônia equatoriana é caracterizada pela produção semicomercial, com agricultura anual para consumo de subsistência (principalmente milho, arroz e banana), assim como café e cacau para a venda em mercados locais. Os colonos têm, geralmente, forte orientação para o mercado e aspiração para investimento em gado (Pichón, 1997; Murphy, 1998).

Há limitada literatura sobre os efeitos de fatores demográficos no desmatamento e uso da terra, focando em aspectos relacionados a ciclos de vida domiciliares. Um exemplo é Walker et al. (2002), que examinam as relações entre uso da terra e ciclo de vida doméstico no Brasil, e Marquette (1998), que observa essas relações para o Equador. Apesar de esses autores não sugerirem um modelo formal, eles discutem como uma função de renda e bemestar domiciliar, dada uma restrição orçamentária e dadas atitudes de aversão ao risco, leva a hipóteses sobre efeitos de preço e alocação de trabalho. Walker et al. (2002, p. 183) revisam vários estudos para a Amazônia e notam que a maioria dos modelos não é completamente especificada e incorpora variáveis endógenas. Os autores utilizam análise de cluster para caracterizar uma área de estudo de 261 domicílios rurais em Rondônia, em sete sistemas agrícolas (por exemplo, especialização em gado, mescla de agricultura anual e de cultivos perenes), e estimam como variáveis demográficas domiciliares e distância afetam a probabilidade de pertencer a um sistema ou a outro. Concluem, então, que fatores demográficos e acessibilidade a mercados são importantes, sugerindo, por exemplo, a necessidade de investigar a relação entre estradas e acesso a mercados. A revisão de vários estudos de caso também indica que fatores como composição e tamanho da família, educação e estado de saúde podem afetar, de forma importante, a decisão por determinado sistema agrícola.

Murphy et al. (1997) utilizam dados de uma pesquisa realizada na área em estudo deste trabalho em 1990 para estimar renda de domicílios rurais. Os autores, porém, pouco discutem a metodologia utilizada para estimar a renda e focam nos fatores determinantes e nas variações de renda e bem-estar das famílias de colonos migrantes. Os autores concluem que mais 
terra, famílias maiores, maior nível educacional e outros fatores como propriedade de terra e posse de determinados bens no lugar anterior de residência apresentam impactos positivos sobre a renda domiciliar. $\mathrm{O}$ presente artigo sugere um avanço em relação ao artigo de Murphy et al. (1997) ao estimar a renda domiciliar com base em dados mais detalhados para 1999 e a evolução da distribuição de renda e terra e ainda comparar mudanças de renda domiciliar nos anos 1990 (período de grande instabilidade política e econômica no País).

Apesar de este artigo propor uma investigação empírica e dessa forma não privilegiar o avanço no estado da arte da discussão teórica sobre determinantes de renda domiciliar rural, vários aspectos devem ser mencionados. Os domicílios rurais investigados não são nem do tipo puro de subsistência (à la Chayanov, discutido em Thorner et al., 1986) nem puramente orientados ao mercado. São, a rigor, uma combinação dos dois e usualmente produzem tanto para a subsistência quanto para o mercado, sendo assim um tipo de "domicílios de economia mista" (conforme termo sugerido por Walker et al., 2002). Esses domicílios rurais de áreas de fronteira são essencialmente caracterizados pela escassez de capital, de forma que a sua renda depende basicamente da quantidade e da qualida- de de terra e do trabalho disponível. A capacidade de geração de renda de trabalhadores individuais tem sido extensamente investigada pela literatura em economia do trabalho e tem sido relacionada à educação, à experiência de trabalho, à ocupação, à idade, ao local de trabalho e ao gênero.

A relevância desses fatores em um contexto como a Amazônia não tem sido investigada de forma aprofundada, apesar de evidências apontarem para um papel pequeno da educação e de uma relevância de ocupação e experiência de trabalho no caso de similaridade entre o tipo de trabalho anterior e o atual. De qualquer forma, a educação pode afetar tanto a probabilidade de uma pessoa procurar trabalho fora do domicílio e lote rural quanto o retorno do trabalho realizado. Assim, pode-se esperar que todos os atributos individuais influenciem a renda não apenas individual, mas também domiciliar. Outro fator importante que afeta a renda domiciliar é a quantidade e a qualidade da terra pertencente ao domicílio, conforme ilustrado pela teoria neoclássica da agricultura domiciliar (Singh et al., 1986; Strauss, 1986; Walker et al., 2002).

\section{3_ Área em estudo}

O Norte da Amazônia equatoriana ("Oriente"), na Amazônia Ocidental, é caracte- 
rizada pela altíssima biodiversidade (Myers et al., 2000), a qual é consideravelmente maior do que em áreas menos úmidas ao leste, no Brasil (Figura 1). Cerca de 45\% do território equatoriano localiza-se na Amazônia, mas contém apenas $5 \%$ da população do País. A Amazônia equatoriana compreende uma área aos pés dos Andes - a cerca de 200 metros acima do nível do mar - até a fronteira com o Peru, ao leste. A área em estudo compreende altitudes entre $350 \mathrm{~m}$ e $250 \mathrm{~m}$, cortando a linha do Equador, com médias anuais de chuva de $3 \mathrm{~m}$ a $5 \mathrm{~m}$, e sem uma estação seca regular.

Desde os anos 1970, a área em estudo tem sido crescentemente ocupada por colonos agrícolas e continua a ser uma "fronteira aberta", atraindo migrantes de outras partes do Equador, especialmente de áreas rurais dos Andes - uma região caracterizada por um sistema agrícola marcado pela dualidade entre alta concentração fundiária e presença de propriedades rurais muito pequenas (com restrição do fator terra para a geração de subsistência de uma família) em que a maioria das famílias não possui a propriedade da terra. O processo inicial de colonização foi favorecido pela descoberta de petróleo, nos anos 1970, nas proximidades da cidade de lago Agrio, o que induziu a criação de infraestrutura - como

\section{Figura 1_Área em estudo no Norte da Amazônia equatoriana}

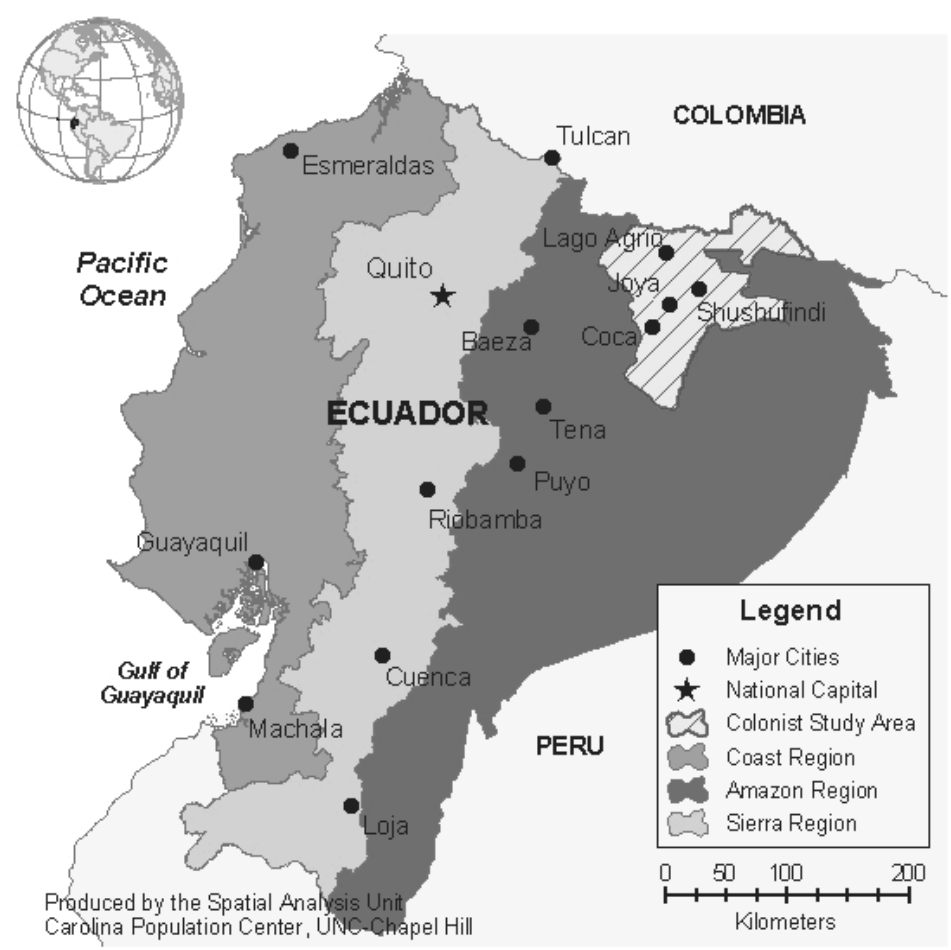

Fonte: Elaboração própria a partir de pesquisa domiciliar longitudinal (anos de 1990 e 1999) realizada pelo Carolina Population Center, University of North Carolina at Chapel Hill (CPC/UNC). 
estradas (Pichón, 1997; Pichón e Bilsborrow, 1999), dutos para escoamento do petróleo e uma série de serviços urbanos - e consequentemente o fluxo intenso de migrantes à procura de terras. Uma das consequências desse processo foi a redução na cobertura florestal de virtualmente 100\% em 1970 para 59\% em 1990, e 45\% em 1999.

Hiraoka e Yamamoto (1980) estimam em 8.000 o número de domicílios rurais criados na região das províncias de Napo e Sucumbíos (que constituem a área em estudo) ao final dos anos 1970. Ao longo do tempo, os colonos usualmente aspiram mover-se do plantio de cultivos anuais de subsistência para um sistema de policultura e posteriormente para a criação de gado, gerando importantes impactos sobre o ecossistema. Bromley (1981) descreve um sistema típico de agricultura na Amazônia equatoriana, conhecida como respaldo, em que os migrantes colonos estabelecem lotes inicialmente ao longo das estradas principais, subsequentemente passam a ocupar lotes de terra paralelos a partir de cerca de 2 quilômetros da estrada, e em seguida 4 quilômetros, 6 quilômetros, 8 quilômetros, e daí em diante. Aos assentados eram fornecidos títulos provisórios de terra pelo Instituto Nacional de Colonização e Reforma Agrária (IERAC). Tais títulos provisórios eram concedidos a partir do momento em que os colonos provavam ter desmatado uma área para o plantio (Murphy, 1998). Os lotes rurais tinham, usualmente, $50 \mathrm{ha}(250 \mathrm{~m}$ de largura e 2 quilômetros de profundidade). Infelizmente, a insegurança fundiária na Amazônia equatoriana aumentou drasticamente após 1994 com o fechamento do IERAC, consequência das reformas neoliberais introduzidas pelo então eleito presidente do País.

Recentemente, a urbanização tem se constituído um importante processo na Amazônia equatoriana. Em 2001, o nível de urbanização (proporção da população residente em áreas urbanas) era de 36\%, contrastando com o menor nível - 26\% verificado em 1990, e de 5\% em 1970 (INEC, 1992 e 2001). A alta taxa de crescimento natural resultante da alta fecundidade, o contínuo fluxo de migrantes e as perspectivas de expansão da indústria petrolífera em função de novas descobertas de reservas de petróleo em anos recentes e de novos investimentos em infraestrutura (como a ampliação da rede de oleodutos) indicam potencial aumento, nos anos posteriores, da migração, das pressões fundiárias e da urbanização. Os resultados da pesquisa realizada na área em estudo no ano de 1999 suportam tais evidências, demonstrando alto crescimento populacional, aumento na fragmentação de lotes rurais e a 
aceleração do processo de formação de solares - pequenos lotes de terra com finalidade apenas residencial, principalmente ao longo de estradas e nas proximidades das cidades locais. Além disso, os residentes em domicílios rurais estão crescentemente adotando estratégias de sobrevivência que incluem alocação de trabalho fora dos lotes rurais de origem, o que é consequência tanto do crescimento do mercado de trabalho urbano quanto do aumento de oportunidades de trabalho rurais (em lotes de maior tamanho) e empregos na indústria petrolífera. Tais processos são associados também à maior pressão sobre a produção nos lotes de origem em função do aumento populacional e da diminuição do tamanho dos lotes, como mencionado acima, e ao declínio dos preços dos principais cultivos agrícolas produzidos na região e direcionados aos mercados, como o café.

\section{Fonte de dados e métodos}

Este artigo utiliza uma base de dados longitudinal de domicílios rurais na Amazônia equatoriana, em 1990 e 1999. Uma amostra probabilística de 418 domicílios rurais foi selecionada em 1990, fornecendo informações sobre composição domiciliar, produção agrícola e insumos, bens e renda gerada por trabalho fora dos domicílios rurais de origem, migração e remessas, entre outras informações. O quadro amostral em 1990, fornecido pelo IERAC, consistia em uma lista de lotes rurais alocada para colonos migrantes. A amostra contém 5,9\% da população assentada de colonos migrantes (418 domicílios rurais), sendo estatisticamente representativa da população assentada em 1990.

Para investigar as várias mudanças que ocorreram na região durante os anos 1990, foi realizado, em 1999, um follow-up da pesquisa de 1990. A pesquisa de 1999 visitou os mesmos lotes rurais em 1990, sendo coletadas informações para 658 domicílios rurais. Esse número, superior ao número de domicílios rurais investigados em 1990, reflete o intenso processo de subdivisão de lotes verificado na região nos anos 1990.

Pesquisas domiciliares em áreas de fronteira usualmente coletam informações não confiáveis sobre renda ou mesmo não formulam tais perguntas. Perguntas do tipo "no todo, qual a renda gerada neste domicílio no último ano (ou mês)" usualmente levam a dados inconsistentes, mesmo que todos no domicílio, acima de certa idade, respondam à pergunta. A forma mais adequada de coleta de informações sobre renda, no contexto de fronteiras agrícolas 
em países em desenvolvimento, é através de perguntas sobre todas as possíveis fontes de renda de todos os membros do domicílio, incluindo renda de trabalho assalariado (temporário ou permanente), e de quaisquer trabalhos secundários; e também renda de atividades econômicas próprias (cozinheiras, atividades técnicas, prestação de serviços, comércio, transporte etc.), e transferências de renda recebidas do governo ou de familiares. Assim, o número de questões, o tempo necessário para coleta e o tipo de treinamento necessário ao entrevistador tornam esse tipo de informação sobre renda praticamente inviável em pesquisas de múltiplas propostas (multi-purpose survey).

Outra questão importante é que domicílios rurais são tanto produtores quanto con- sumidores da produção agrícola, de forma que a coleta de informação sobre a produção vendida leva a estimativas subestimadas de renda. Esse é particularmente o caso dos mais pobres (que vendem menos ao mercado e consomem a maior parte da produção) do que o dos mais ricos, que provavelmente possuem maiores lotes e praticam monoculturas com a produção orientada ao mercado. Assim, é necessário formular perguntas sobre produção total, e não aquela direcionada ao mercado. No caso da área em estudo, a maior parte dos domicílios rurais pratica determinados cultivos para o próprio consumo, sendo que o valor desses cultivos deve ser estimado ou imputado e constituirá parcela importante da renda domiciliar, especialmente para aqueles associados a pequenos lotes rurais. Sem essa inclusão do consumo de subsistência, a renda total será subestimada e levará a vieses entre domicílios mais pobres e mais ricos e consequentemente em medidas de pobreza e desigualdade exageradas.

Tendo em vista essa perspectiva, a estimativa de renda domiciliar foi realizada em 1990 e 1999, tanto para fontes de renda geradas a partir dos lotes rurais (on-farm income) quanto para aquelas geradas fora dos lotes (off-farm income). Para o primeiro conjunto de fontes de renda, a estimação é mais complexa e é baseada na quantidade produzida (em diferentes unidades) de cada cultivo nos últimos doze meses, incluindo pequenas produções de frutas e vegetais. Questões sobre renda nos últimos doze meses pela venda de animais grandes ou pequenas (gado, animais domésticos como porcos e galinhas) são complementadas por informações sobre a venda de produtos animais, como ovos e leite. Outras fontes de renda geradas no lote rural incluem aluguel de terra ou de animais, venda de produtos madeireiros, peixes ou outros produtos coletados na floresta. Infelizmente, a estimativa de renda de venda de made- 
ira é frequentemente subestimada tendo em vista que tal atividade é, na maioria dos casos, ilegal.

A renda gerada fora do lote rural consiste principalmente em renda de trabalho assalariado de um membro do domicílio que exerceu alguma atividade nos últimos doze meses antes da data da entrevista. Tal atividade pode ser tanto agrícola quanto não agrícola, como, por exemplo, a renda gerada em uma pequena venda ou estabelecimento comercial (tienda) ou pelo trabalho em uma cidade próxima (o que envolve uma diversidade de ocupações possíveis). O trabalho assalariado é bastante comum na região: cerca de $40 \%$ dos domicilios rurais possuíam pelo menos um de seus membros nessa atividade em 1990 (quando o tamanho dos lotes era praticamente intacto, com tamanho médio de 45ha), e cerca de $60 \%$ em 1999, quando muitos lotes já se encontravam divididos. Fontes menos frequentes de renda eram obtidas através do aluguel de veículos ou equipamentos, aplicações financeiras, venda de lenha ou atividades relacionadas ao turismo. Por fim, remessas de migrantes (indivíduos que previamente moravam no domicílio rural) também são somadas à renda domiciliar total, embora seja uma fonte de renda menos frequente na região.
Vários procedimentos foram utilizados para a estimativa de renda domiciliar, incluindo imputação de valores de quantidades produzidas para o caso de informação não declarada (baseado, por exemplo, no nível de produção em lotes próximos de iguais características, como tamanho da terra, e onde há redes de parentesco, ou no nível médio de preço de mercado de determinado cultivo, quando a informação de preço de venda por unidade não é fornecida). De qualquer forma, tais imputações não constituíram parcelas significantes do total da renda domiciliar na região. A presença de alguns outliers também não representou problema para o uso das médias, como será demonstrada na próxima seção.

Uma vez estimada a renda domiciliar para cada domicílio rural, valendo-se das pesquisas de 1990 e 1999, pode-se analisar como tais domicílios sofreram declínio ou aumento em seu nível médio de renda no período. Tal procedimento envolveu o ajuste da renda pela alta inflação no período, com o declínio no poder de compra da moeda em 1990, sucre, e a estimativa de seu equivalente em dólares em 1990 para tornar os dados comparáveis no tempo (a economia equatoriana foi dolarizada nos anos 1990). 


\section{Resultados}

\section{1_Características populacionais}

A Tabela 1 traz a comparação de indicadores demográficos para domicílios rurais na área em estudo em 1990 e 1999. Em 1990, o tamanho médio do lote rural associado a um domicílio rural era de 6,6, e a população era tipicamente jovem - com 40,6\% abaixo de 12 anos de idade. A alta Razão de Dependência - 0,79 - revela um alto regime de fecundidade prevalecendo até 1990, com a composição etária da população indicando uma modesta população em idade de trabalho em relação ao alto número de crianças dependentes (e uma pequena proporção de população idosa, indicando uma relativamente baixa expectativa de vida ao nascer). A Razão de Dependência é praticamente a mesma em 1999, demonstrando pouca mudança na relação entre população em idade de trabalho e dependentes; porém, o tamanho médio do domicílio é menor $-5,8$. Esses resultados indicam numa estrutura etária jovem na área em estudo, o que é consistente com a existência de várias subdivisões de lotes desde 1990, as quais são ocupadas majoritariamente por casais jovens.

A idade média do chefe do domicílio e de sua esposa apresenta pouca variação entre 1990 e 1999, refletindo o fato de que o envelhecimento em nove anos dos chefes e das esposas em 1990 é compensado por uma mudança de composição em alguns domicílios, com os filhos ou filhas do chefe em 1990 assumindo a chefia nove anos depois, ou mesmo imigrantes mais jovens que chegam à região e assumem um dos domicílios da amostra. Há ainda aumento substancial na educação da população: a população acima de seis anos de idade em 1990 que possuía pelo menos primário completo era mais de 50\% em 1999 contra $44 \%$ em 1990, enquanto a proporção com alguma educação secundária cresceu de 12\% em 1990 para 19\% em 1999. Esses números refletem um efeito importante de oferta educacional, tendo em vista a construção de escolas em diversas comunidades na área em estudo durante os anos 1990.

A Tabela 1 indica, durante a década, pequena queda na Razão de Sexo, o que contribuiu para maior equilíbrio entre homens e mulheres na região. Esse é um processo típico de evolução no tempo em áreas de fronteira, como na Amazônia, em que formas iniciais de ocupação e uso do solo estão relacionadas a uma maior seletividade de migração masculina. Por outro lado, essa seletividade é relativamente menor na Amazônia equatoriana comparada a outras áreas de fronteira, como na Amazô- 
nia brasileira, pelo fato de a primeira ter sido associada majoritariamente à migração de famílias, enquanto na segunda era típica a migração masculina em um primeiro estágio (com o restante da família reunindose após o estágio inicial de adaptação do chefe na fronteira). Outro aspecto demográfico relevante é a queda na Taxa de Fecundidade Total (número médio de filhos por mulher), de aproximadamente 8 em 1990 (Thapa, Bilsborrow e Murphy, 1995), para aproximadamente 5 em 1999.

Tabela 1_ Indicadores demográficos selecionados, Norte da Amazônia equatoriana - 1990 e 1999

\begin{tabular}{|c|c|c|}
\hline Indicador & 1990 & 1999 \\
\hline População (N) & 2.761 & 3.835 \\
\hline Domicílios $(\mathrm{N})$ & 416 & $652^{\mathrm{a}}$ \\
\hline Tamanho Médio do Domicílio & 6,6 & 5,8 \\
\hline \multicolumn{3}{|l|}{ Grupos Etários (\%) } \\
\hline Idade $<12$ & 40,6 & 40,4 \\
\hline $12 \leq$ idade $<65$ & 55,9 & 56,9 \\
\hline Idade $\geq 65$ & 3,5 & 2,7 \\
\hline Razão de Dependênciab & 0,79 & 0,76 \\
\hline Idade Média do Chefe de Domicílio (anos) & 44 & 43 \\
\hline Idade Média da Esposa do Chefe (anos) & 39 & 37 \\
\hline Razão de Sexoc & 1,22 & 1,19 \\
\hline \multicolumn{3}{|l|}{ Educação (\%) } \\
\hline Nenhuma & 7,2 & 6,5 \\
\hline Primário Incompleto & 48,4 & 41,0 \\
\hline Primário Completo & 32,6 & 33,7 \\
\hline Secundário Incompleto & 8,4 & 14,2 \\
\hline Secundário Completo ou Superior & 3,4 & 4,6 \\
\hline TFT & 8,0 & 5,0 \\
\hline
\end{tabular}

(a) Não incluindo dados incompletos de 109 solares.

(b) Taxa da população abaixo de 15 anos e acima de 64 anos em relação à população entre 15 e 64 anos.

(c) Razão entre homens e mulheres.

Fonte: Elaboração própria a partir de pesquisa domiciliar longitudinal (anos de 1990 e 1999) realizada pelo Carolina Population Center, University of North Carolina at Chapel Hill (CPC/UNC). 


\section{2_ Renda domiciliar rural}

As Tabelas $2 \mathrm{a}$ e $2 \mathrm{~b}$ mostram as estimativas de renda domiciliar rural para 1990 e 1999, respectivamente. Os resultados são apresentados para dez categorias de tamanho de lote e para todos os lotes, assim como por tipo de renda: renda produzida no lote rural (através de cultivos anuais e perenes, criação de gado e de outros animais, e extração de madeira), e renda produzida fora do lote (em grande parte por meio de trabalho assalariado, mas também por remessas e aluguel de terra ou animais). As tabelas também mostram a renda média domiciliar para cada categoria de tamanho de terra, e por tipo de renda, e a consequente renda média per capta em valores de dólares de 1999. A Tabela 2c compara as mudanças no tempo (em percentagem) dos dados apresentados nas Tabelas $2 \mathrm{a}$ e $2 \mathrm{~b}$.

Os resultados apontam mudanças importantes tanto na renda domiciliar quanto no tamanho do domicílio no período em análise. Em primeiro lugar, a renda média é reduzida em cerca de $30 \%$, sendo tal queda registrada em seis das dez categorias de tamanho do lote e compreendendo dois terços dos domicílios. A redução não foi verificada para domicílios em categorias intermediárias de 10 ha a 30 ha (ignorando o grupo de 5 ha a 10 ha, com apenas nove observações), provavelmente porque tais domicilios eram mais incentivados a diversificar as fontes de renda em relação a domicílios maiores (Pichón e Bilsborrow, 1999). Ao mesmo tempo, a renda per capta diminuiu em 21\% em grande parte graças ao declínio no tamanho domiciliar entre 1990 e 1999, sendo esse declínio de $12 \%$ no agregado (com resultados variados entre categorias de tamanho do lote). Para as duas categorias intermediárias de 10 ha a $30 \mathrm{ha}$, e para a categoria de 50 ha a $90 \mathrm{ha}$, a renda média per capta foi maior em 1990 em relação a 1999. A queda para os lotes entre 50ha a 60ha, porém, está associada à queda no tamanho do domicílio. Em geral, o declínio no tamanho médio do domicílio compensou em cerca de um terço a queda na renda domiciliar, para o cômputo da renda média domiciliar per capta.

O processo de fragmentação de lotes durante os anos 1990 também afetou a forma como os colonos geram suas rendas. A Tabela 2a sugere, como esperado, que, quanto menor o lote, maior a proporção de renda gerada fora do lote em 1999. Essa tendência já surge em 1990, se as categorias de lotes rurais com menos de vinte observações são ignoradas, e as duas maiores categorias são integradas (Tabela $2 \mathrm{~b}$ ). 
Tabela 2a_ Renda domiciliar rural produzida no lote e fora do lote, tamanho médio do domicílio, e renda "per capta", por categoria de tamanho do lote - Norte da Amazônia equatoriana, 1999

\begin{tabular}{|c|c|c|c|c|c|c|}
\hline $\begin{array}{l}\text { Tamanho } \\
\text { do Lote (ha) }\end{array}$ & N & $\begin{array}{l}\text { Renda Domiciliar } \\
\text { Média (\$ US) }\end{array}$ & $\begin{array}{l}\text { Tamanho Médio } \\
\text { do Domicílio }\end{array}$ & $\begin{array}{c}\text { Renda "per capta" } \\
\text { (\$ US) }\end{array}$ & $\begin{array}{c}\text { Renda no Lote } \\
\text { (\%) }\end{array}$ & $\begin{array}{l}\text { Renda Fora } \\
\text { do Lote (\%) }\end{array}$ \\
\hline $0-2$ & 38 & 482,2 & 5,2 & 92,4 & 14,6 & 85,4 \\
\hline $2-5$ & 128 & 778,7 & 5,0 & 155,4 & 38,0 & 62,0 \\
\hline $5-10$ & 74 & 1017,2 & 5,1 & 197,9 & 51,3 & 48,7 \\
\hline $10-20$ & 62 & 995,8 & 5,7 & 174,4 & 70,4 & 29,6 \\
\hline $20-30$ & 69 & 1275,4 & 6,2 & 205,1 & 57,6 & 42,4 \\
\hline $30-40$ & 81 & 1402,1 & 6,4 & 219,4 & 58,9 & 41,1 \\
\hline $40-50$ & 146 & 1640,6 & 6,1 & 267,6 & 58,2 & 41,8 \\
\hline $50-60$ & 34 & 2161,7 & 6,7 & 325,1 & 69,8 & 30,2 \\
\hline $60-90$ & 18 & 4013,7 & 6,7 & 597,3 & 61,0 & 39,0 \\
\hline Mais de 90 & 8 & 2126,6 & 6,3 & 337,6 & 63,8 & 36,2 \\
\hline Total & 658 & $1305,2$. & 5,8 & 225,0 & 56,6 & 43,4 \\
\hline
\end{tabular}

Fonte: Elaboração própria a partir de pesquisa domiciliar longitudinal (anos de 1990 e 1999)

realizada pelo Carolina Population Center, University of North Carolina at Chapel Hill (CPC/UNC).

Tabela 2b_ Renda domiciliar rural produzida no lote e fora do lote, tamanho médio do domicílio, e renda "per capta", por categoria de tamanho do lote - Norte da Amazônia equatoriana, 1990

\begin{tabular}{|c|c|c|c|c|c|c|}
\hline $\begin{array}{c}\text { Tamanho } \\
\text { do Lote (ha) }\end{array}$ & $\mathbf{N}$ & $\begin{array}{l}\text { Renda Domiciliar } \\
\text { Média (\$ US) }\end{array}$ & $\begin{array}{c}\text { Tamanho Médio } \\
\text { do Domicílio }\end{array}$ & $\begin{array}{c}\text { Renda "per capta" } \\
\text { (\$ US) }\end{array}$ & $\begin{array}{c}\text { Renda no Lote } \\
\text { (\%) }\end{array}$ & $\begin{array}{l}\text { Renda Fora } \\
\text { do Lote }(\%)\end{array}$ \\
\hline $0-2$ & 8 & 840,4 & 6,6 & 126,9 & 86,1 & 13,9 \\
\hline $2-5$ & 13 & 887,5 & 5,2 & 169,7 & 69,8 & 30,2 \\
\hline $5-10$ & 9 & 439,5 & 4,3 & 101,5 & 87,4 & 12,6 \\
\hline $10-20$ & 23 & 801,4 & 5,5 & 145,2 & 59,3 & 40,8 \\
\hline $20-30$ & 38 & 1137,3 & 6,5 & 175,0 & 76,5 & 23,5 \\
\hline $30-40$ & 78 & 1719,4 & 6,2 & 275,5 & 60,1 & 39,9 \\
\hline $40-50$ & 166 & 1842,1 & 6,5 & 282,5 & 75,2 & 24,8 \\
\hline $50-60$ & 53 & 2346,3 & 7,7 & 306,3 & 78,2 & 21,8 \\
\hline $60-90$ & 12 & 2692,4 & 6,7 & 404,3 & 83,1 & 16,9 \\
\hline Mais de 90 & 18 & 5685,2 & 8,9 & 640,2 & 83,8 & 16,2 \\
\hline
\end{tabular}

Fonte: Elaboração própria a partir de pesquisa domiciliar longitudinal (anos de 1990 e 1999) realizada pelo Carolina Population Center, University of North Carolina at Chapel Hill (CPC/UNC). 
Em geral, a maioria dos domicílios em 1990 obteve a maior parte de sua renda no próprio lote (74\%), enquanto em 1999 essa percentagem cai significativamente (para 57\%) em função da maior importância de fontes geradas fora do lote. Tal resultado é explicado por duas grandes mudanças na Amazônia equatoriana durante os anos 1990. Em primeiro lugar, os preços caíram para as duas principais commodities agrícolas produzidas na região - café e carne bovina -, o que levou vários colonos a procurarem alternativas de renda fora do lote como forma de complementação da renda. Em segundo lugar, e como discutido anteriormente, a área em estudo experimentou um processo amplo de fragmentação de lotes durante os anos 1990, tanto para acomodar pressões endógenas relacionadas ao crescimento populacional e estágios de ciclo de vida (à medida que filhos e filhas dos colonos pioneiros atingem idades adultas e demandam as próprias terras) quanto pressões exógenas associadas à venda de terras para novos migrantes que chegam à região (Barbieri, 2005). Como demonstrado na Tabela 2c, houve grande aumento na proporção de pequenos lotes rurais (até $30 \mathrm{ha}$, mas especialmente abaixo de 10ha) e acentuado declínio no número de grandes lotes, como resultado da fragmentação de terras.

As Tabelas 3a, 3b e 3c mostram a distribuição de domicílios rurais por cate- goria de renda em vez de tamanho do lote para os anos de 1990 e 1999. Os resultados mostram um deslocamento de grande parte dos domicilios para as categorias de menor renda, com aproximadamente metade de todos os domicílios apresentando renda inferior a U\$ 700 em 1999 comparados a $35 \%$ em 1990, ao passo que aqueles com renda acima de U\$ 2.500 passam de 18,3\% para $12,5 \%$. Domicílios maiores tendem a apresentar maior renda por ano, de forma que as diferenças na renda domiciliar per capta são menores que as diferenças nos níveis de renda média através das categorias de renda. Entretanto, os domicílios mais pobres tendem a apresentar menores declínios no tamanho médio do domicílio ao longo do tempo do que nos domićlios de maior renda, o que sugere uma associação entre pobreza e declínio da fecundidade. Em relação às mudanças ao longo do tempo (Tabela 3c), observa-se, em primeiro lugar, que as rendas domiciliares médias diminuem cerca de um terço $(30,5 \%)$, mas, ao mesmo tempo, a renda média de domicílios em cada categoria de renda diminui menos do que isso, havendo até aumento para metade das categorias de renda domiciliar. Uma explicação plausível para isso, como notado anteriormente, é o fato de que a distribuição geral de domicílios mudou substancialmente no período em direção às categorias de menor renda domiciliar. 
Tabela 2c_ Mudança percentual na renda domiciliar rural produzida no lote e fora do lote, tamanho médio do domicílio, e renda "per capta", por categoria de tamanho do lote - Norte da Amazônia equatoriana, 1990 a 1999

\begin{tabular}{|c|c|c|c|c|c|c|}
\hline $\begin{array}{l}\text { Tamanho } \\
\text { do Lote (ha) }\end{array}$ & $\mathbf{N}$ & $\begin{array}{c}\text { Renda Domiciliar } \\
\text { Média }\end{array}$ & $\begin{array}{l}\text { Tamanho Médio } \\
\text { do Domicílio }\end{array}$ & $\begin{array}{l}\text { Renda } \\
\text { "per capta" }\end{array}$ & $\begin{array}{l}\text { Renda Média Gerada } \\
\text { Fora do Lote }\end{array}$ & $\begin{array}{l}\text { Renda Média } \\
\text { Gerada no Lote }\end{array}$ \\
\hline $0-2$ & 375,0 & $-42,6$ & $-21,1$ & $-27,2$ & $-90,3$ & $-83,1$ \\
\hline $2-5$ & 884,6 & $-12,3$ & $-4,2$ & $-8,4$ & $-52,3$ & $-45,6$ \\
\hline $5-10$ & 722,2 & 131,4 & 18,7 & 94,9 & 35,8 & $-41,3$ \\
\hline $10-20$ & 169,6 & 24,3 & 3,4 & 20,1 & 47,6 & 18,7 \\
\hline $20-30$ & 81,6 & 12,1 & $-4,3$ & 17,2 & $-15,6$ & $-24,8$ \\
\hline $30-40$ & 3,8 & $-18,5$ & 2,4 & $-20,4$ & $-20,1$ & $-2,0$ \\
\hline $40-50$ & $-12,0$ & $-10,9$ & $-6,0$ & $-5,3$ & $-31,1$ & $-22,6$ \\
\hline $50-60$ & $-35,8$ & $-7,9$ & $-13,2$ & 6,1 & $-17,8$ & $-10,8$ \\
\hline $60-90$ & 50,0 & 49,1 & 0,9 & 47,7 & 9,5 & $-26,6$ \\
\hline Mais de 90 & $-55,6$ & $-62,6$ & $-29,1$ & $-47,3$ & $-71,5$ & $-23,9$ \\
\hline Total & 58,17 . & $-30,49$ & $-11,72$ & $-21,26$ & $-47,08$ & $-23,87$. \\
\hline
\end{tabular}

Fonte: Elaboração própria a partir de pesquisa domiciliar longitudinal (anos de 1990 e 1999)

realizada pelo Carolina Population Center, University of North Carolina at Chapel Hill (CPC/UNC).

Tabela 3a_ Renda domiciliar rural produzida no lote e fora do lote, tamanho médio do domicílio, e renda "per capta", por categoria de renda - Norte da Amazônia equatoriana, 1999

\begin{tabular}{|c|c|c|c|c|c|c|}
\hline $\begin{array}{l}\text { Renda Anual } \\
\text { (U\$) }\end{array}$ & N & $\begin{array}{l}\text { Renda Domiciliar } \\
\text { Média (\$ US) }\end{array}$ & $\begin{array}{l}\text { Tamanho Médio } \\
\text { do Domicílio }\end{array}$ & $\begin{array}{c}\text { Renda } \\
\text { "per capta" (\$ US) }\end{array}$ & $\begin{array}{c}\text { Renda no Lote } \\
(\%)\end{array}$ & $\begin{array}{l}\text { Renda Fora } \\
\text { do Lote }(\%)\end{array}$ \\
\hline Menos de 100 & 44 & 32,4 & 5,4 & 6,0 & 70,2 & 29,8 \\
\hline $100-400$ & 142 & 250,4 & 4,6 & 54,0 & 72,1 & 27,9 \\
\hline $400-700$ & 133 & 559,3 & 5,5 & 101,5 & 67,4 & 32,6 \\
\hline $700-1000$ & 80 & 847,1 & 5,9 & 144,8 & 72,1 & 27,9 \\
\hline $1000-1500$ & 87 & 1216,9 & 6,8 & 179,0 & 56,0 & 44,0 \\
\hline $1500-2500$ & 90 & 1926,3 & 5,9 & 324,3 & 57,1 & 42,9 \\
\hline $2500-3500$ & 37 & 2973,4 & 6,3 & 472,7 & 54,7 & 45,3 \\
\hline $3500-5000$ & 22 & 4129,8 & 6,4 & 645,3 & 52,4 & 47,6 \\
\hline $5000-6500$ & 14 & 5735,8 & 8,8 & 653,3 & 42,3 & 57,7 \\
\hline Mais de 6500 & 9 & 13256,8 & 9,4 & 1404,3 & 50,3 & 49,7 \\
\hline . Total . . & 658 & 1305,2 & 5,8 & 225,8 . & $56,6$. & 43,4 \\
\hline
\end{tabular}

Fonte: Elaboração própria a partir de pesquisa domiciliar longitudinal (anos de 1990 e 1999)

realizada pelo Carolina Population Center, University of North Carolina at Chapel Hill (CPC/UNC). 
Tabela 3b_ Renda domiciliar rural produzida no lote e fora do lote, tamanho médio do domicílio, e renda "per capta", por categoria de renda Norte da Amazônia equatoriana, 1990

\begin{tabular}{|c|c|c|c|c|c|c|}
\hline $\begin{array}{l}\text { Renda Annual } \\
\text { (U\$) }\end{array}$ & $\mathbf{N}$ & $\begin{array}{l}\text { Renda Domicilia } \\
\text { Média (\$ US) }\end{array}$ & $\begin{array}{l}\text { Tamanho Médio } \\
\text { do Domicílio }\end{array}$ & $\begin{array}{c}\text { Renda "per capta" } \\
\text { (\$ US) }\end{array}$ & $\begin{array}{c}\text { Renda no Lote } \\
(\%)\end{array}$ & $\begin{array}{l}\text { Renda Fora } \\
\text { do Lote }(\%)\end{array}$ \\
\hline Menos de 100 & 17 & 38,3 & 5,0 & 7,7 & 88,4 & 11,6 \\
\hline $100-400$ & 53 & 269,1 & 5,2 & 52,3 & 90,7 & 9,4 \\
\hline $400-700$ & 76 & 548,7 & 5,9 & 93,6 & 83,6 & 16,4 \\
\hline $700-1000$ & 58 & 819,3 & 6,0 & 137,0 & 83,0 & 17,0 \\
\hline $1000-1500$ & 66 & 1229,2 & 7,5 & 163,2 & 82,6 & 17,4 \\
\hline $1500-2500$ & 72 & 1881,5 & 7,1 & 265,7 & 81,1 & 18,9 \\
\hline $2500-3500$ & 26 & 2921,4 & 7,1 & 413,2 & 70,3 & 29,7 \\
\hline $3500-5000$ & 24 & 4183,4 & 7,6 & 551,9 & 76,9 & 23,1 \\
\hline $5000-6500$ & 10 & 7422,2 & 9,6 & 773,1 & 76,5 & 23,5 \\
\hline Mais de 6500 & 16 & 13115,0 & 8,1 & 1615,2 & 61,1 & 38,9 \\
\hline Total & 416 & 1877,8 & 6,6 & 285,8 . & 74,3 . & 25,7 . \\
\hline
\end{tabular}

Fonte: Elaboração própria a partir de pesquisa domiciliar longitudinal (anos de 1990 e 1999)

realizada pelo Carolina Population Center, University of North Carolina at Chapel Hill (CPC/UNC).

Tabela 3c_ Mudança percentual na renda domiciliar rural produzida no lote e fora do lote, tamanho médio do domicílio, e renda "per capta", por categoria de renda - Norte da Amazônia equatoriana, 1990 a 1999

\begin{tabular}{|c|c|c|c|c|c|c|}
\hline $\begin{array}{l}\text { Renda Anual } \\
\text { (U\$) }\end{array}$ & $\mathbf{N}$ & $\begin{array}{c}\text { Renda Domiciliar } \\
\text { Média }\end{array}$ & $\begin{array}{c}\text { Tamanho Médio } \\
\text { do Domicílio }\end{array}$ & $\begin{array}{l}\text { Renda } \\
\text { "per capta" }\end{array}$ & $\begin{array}{c}\text { Renda Média Gerada } \\
\text { Fora do Lote }\end{array}$ & $\begin{array}{l}\text { Renda Média } \\
\text { Gerada no Lote }\end{array}$ \\
\hline Menos de 100 & 158,8 & $-15,2$ & 8,2 & $-21,6$ & $-32,7$ & $-20,6$ \\
\hline $100-400$ & 167,9 & $-7,0$ & $-9,9$ & 3,3 & $-26,1$ & $-20,6$ \\
\hline $400-700$ & 75,0 & 1,9 & $-6,0$ & 8,4 & $-17,8$ & $-19,4$ \\
\hline $700-1000$ & 37,9 & 3,4 & $-2,2$ & 5,7 & $-10,2$ & $-13,1$ \\
\hline $1000-1500$ & 31,8 & $-1,0$ & $-9,7$ & 9,6 & $-32,9$ & $-32,2$ \\
\hline $1500-2500$ & 25,0 & 2,4 & $-16,1$ & 22,0 & $-27,9$ & $-29,6$ \\
\hline $2500-3500$ & 42,3 & 1,8 & $-11,0$ & 14,4 & $-20,8$ & $-22,2$ \\
\hline $3500-5000$ & $-8,3$ & $-1,3$ & $-15,6$ & 16,9 & $-32,8$ & $-31,9$ \\
\hline $5000-6500$ & 40,0 & $-22,7$ & $-8,5$ & $-15,5$ & $-57,3$ & $-44,7$ \\
\hline Mais de 6500 & $-43,8$ & 1,1 & 16,3 & $-13,1$ & $-16,8$ & $-17,7$ \\
\hline Total. & 58,2 & $-30,5$ & $-12,0$ & $-21,0$ & $-47,1$ & $-23,9$ \\
\hline
\end{tabular}

Fonte: Elaboração própria a partir de pesquisa domiciliar longitudinal (anos de 1990 e 1999)

realizada pelo Carolina Population Center, University of North Carolina at Chapel Hill (CPC/UNC). 
Uma vez consideradas as mudanças no tamanho médio dos domićlios em diferentes categorias de renda, nota-se uma queda na renda per capta para apenas a menor e maior categoria de renda, as quais correspondem, respectivamente, 6,7 e 3,5\% dos domicílios rurais. Para todas as outras categorias de renda, que correspondem a $90 \%$ do total, há aumento na renda média per capta, e o tamanho médio dos domicílios diminui em maior intensidade comparado à queda na renda, gerando uma espécie de "dividendo demográfico". De qualquer forma, a renda média per capta geral cai em cerca de $30 \%$, em função da entrada de domicílios rurais em categorias de menor tamanho de lote e de renda durante os anos 1990. Por fim, a Tabela $3 \mathrm{c}$ mostra declínios tanto na renda gerada no lote quanto na renda gerada fora do lote, principalmente em função do deslocamento de domicílios para categorias de menor renda, e, em parte, em razão do declínio no tamanho médio do domicílio.

As Tabelas 4a e 4b desagregam ainda mais os dados por tipo de renda gerada, por tamanho do lote rural. As categorias de renda são café (que incluem outros, embora não muito comuns, cultivos perenes como cacau e palma africana), cultivos anuais, gado (incluindo, em pequena proporção, equinos), pequenos animais (galinhas, porcos, porcosda-índia, patos, com dados disponíveis ape- nas para 1999), madeira, e renda gerada fora do lote. As fontes de renda em 1990 (Tabela 4a) já eram bastante diversificadas para o conjunto dos domicílios e lotes rurais, com a criação de gado compreendendo $28 \%$ do total, seguido por renda fora do lote $(26 \%)$, café $(24 \%)$, cultivos anuais $(22 \%)$, e madeira (1\%). É clara ainda a importância de café e cultivos anuais para domicilios com menos de 10 ha (em função do consumo de subsistência de grande parte dos cultivos anuais), e da importância do trabalho assalariado fora do lote para domicílios com até 40ha. A criação de gado é a fonte predominante de renda para domicílios em lotes rurais acima de 50ha (na região amazônica, é necessário cerca de 1 ha de terra para cada cabeça de gado, o que torna a criação de grandes animais inviável em pequenos lotes).

A Tabela 4b apresenta os resultados para 1999 e sugere mudanças importantes em relação a 1990. Em primeiro lugar, há uma mudança na participação das fontes de renda, com a renda gerada fora do lote (majoritariamente através de trabalho assalariado), representando $38 \%$ da renda, café com $16 \%$, gado com $15 \%$, outros cultivos com $12 \%$, madeira com $13 \%$, e pequenos animais representando $5 \%$ das fontes de renda. Apesar de os dados sobre extração de madeira serem mais confiáveis em relação a 1990, há ainda problemas de subestimação pelas razões mencionadas anteriormente. 
Tabela 4a_Renda média domiciliar rural e distribuição percentual por tamanho de lote - Norte da Amazônia equatoriana, 1990

\begin{tabular}{|c|c|c|c|c|c|c|c|}
\hline \multirow{2}{*}{$\begin{array}{c}\text { Tamanho } \\
\text { do Lote (ha) }\end{array}$} & \multirow{2}{*}{$\begin{array}{c}\text { Renda } \\
\text { Domiciliar Média }\end{array}$} & \multirow{2}{*}{$\begin{array}{c}\text { Número de } \\
\text { Domicílios Rurais }\end{array}$} & \multicolumn{5}{|c|}{ Renda Domiciliar Rural (\%) } \\
\hline & & & Café & Outros Cultivos ${ }^{(a)}$ & Gado & Madeira & Fora do Lote \\
\hline $0-2$ & 840,35 & 8 & 37,68 & 45,46 & 1,98 & 0,99 & 13,89 \\
\hline $2-5$ & 887,52 & 13 & 44,54 & 19,50 & 5,47 & 0,29 & 30,20 \\
\hline $5-10$ & 439,53 & 9 & 53,39 & 26,42 & 7,54 & 0,00 & 12,64 \\
\hline $10-20$ & 801,35 & 23 & 23,83 & 19,63 & 14,98 & 0,72 & 40,79 \\
\hline $20-30$ & 1137,25 & 38 & 33,78 & 19,81 & 21,50 & 1,40 & 23,51 \\
\hline $30-40$ & 1719,35 & 78 & 24,82 & 16,88 & 17,69 & 0,67 & 39,94 \\
\hline $40-50$ & 1841,73 & 166 & 26,00 & 26,95 & 21,51 & 0,74 & 24,80 \\
\hline $50-60$ & 2346,31 & 53 & 20,86 & 19,53 & 37,14 & 0,66 & 21,79 \\
\hline $60-90$ & 2692,42 & 12 & 15,60 & 20,17 & 46,10 & 1,19 & 16,94 \\
\hline Mais de 90 & 5685,20 & 18 & 12,64 & 16,77 & 53,38 & 1,03 & 16,17 \\
\hline Total. & 1877,38 & 416. & $23,67$. & 21,86 & 27,95 & 0,80 . & 25,72 \\
\hline
\end{tabular}

(a) Inclui renda de todos os cultivos anuais, semianuais e perenes, além de café.

Fonte: Elaboração própria a partir de pesquisa domiciliar longitudinal (anos de 1990 e 1999)

realizada pelo Carolina Population Center, University of North Carolina at Chapel Hill (CPC/UNC).

Tabela 4b_Renda média domiciliar rural e distribuição percentual por tamanho de lote - Norte da Amazônia equatoriana, 1999

\begin{tabular}{|c|c|c|c|c|c|c|c|c|}
\hline \multirow{2}{*}{$\begin{array}{c}\text { Tamanho } \\
\text { do Lote (ha) }\end{array}$} & \multirow{2}{*}{$\begin{array}{c}\text { Renda } \\
\text { Domiciliar Média }\end{array}$} & \multirow{2}{*}{$\begin{array}{c}\text { Número de } \\
\text { Domicílios Rurais }\end{array}$} & \multicolumn{6}{|c|}{ Renda Domiciliar Rural (\%) } \\
\hline & & & Café & Outros Cultivos(a) & Gado & Outros Animais & Madeira & Fora do Lote ${ }^{(b)}$ \\
\hline $0-2$ & 483,56 & 38 & 6,74 & 2,82 & 0,49 & 4,80 & 0,00 & 85,16 \\
\hline $2-5$ & 1191,43 & 128 & 8,36 & 9,26 & 2,11 & 4,11 & 35,63 & 40,54 \\
\hline $5-10$ & 1132,73 & 74 & 19,83 & 11,04 & 5,89 & 9,04 & 10,43 & 43,77 \\
\hline $10-20$ & 1089,43 & 62 & 29,47 & 15,57 & 8,49 & 9,75 & 9,64 & 27,09 \\
\hline $20-30$ & 1511,66 & 69 & 15,30 & 18,96 & 7,16 & 5,00 & 17,77 & 35,81 \\
\hline $30-40$ & 1452,52 & 81 & 17,27 & 12,12 & 22,54 & 4,14 & 4,25 & 39,68 \\
\hline $40-50$ & 1795,59 & 146 & 16,80 & 11,07 & 19,18 & 3,82 & 10,94 & 38,19 \\
\hline $50-60$ & 2220,25 & 34 & 10,06 & 15,74 & 35,48 & 5,87 & 3,45 & 29,40 \\
\hline $60-90$ & 4475,56 & 18 & 10,13 & 12,10 & 27,69 & 1,30 & 13,78 & 34,99 \\
\hline Mais de 90 & 2289,99 & 8 & 38,33 & 9,82 & 11,18 & 2,97 & 4,07 & 33,62 \\
\hline Total & 1481,48 & 658. & 15,76 & $.12,40$. & 15,32 & $4,87$. & $13,38$. & 38,28 . \\
\hline
\end{tabular}

(a) Inclui renda de todos os cultivos anuais, semianuais e perenes, além de café

(b) A diferença entre a renda total média nessa tabela e o resultado na Tabela 3a é devido à não incorporação, nesta última,

da renda produzida no lote com base em (a partir de) outros animais.

Fonte: Elaboração própria a partir de pesquisa domiciliar longitudinal (anos de 1990 e 1999)

realizada pelo Carolina Population Center, University of North Carolina at Chapel Hill (CPC/UNC). 
As duas maiores mudanças estão no aumento da dependência do trabalho assalariado e no declínio da importância do gado, a qual é a maior fonte de renda apenas para lotes entre $50 \mathrm{ha} \mathrm{e} 60 \mathrm{ha}$. O cultivo de café, assim como a extração de madeira, continua a ser moderadamente importante para várias categorias. Aparentemente, famílias mais pobres, com pouca terra disponível, mantêm na extração de madeira uma parte importante da renda (assim como na venda de pequenos animais e trabalho assalariado). Isso pode ser explicado pela combinação entre baixa renda e, possivelmente, a extração de madeira ilegal de áreas de preservação ou em lotes rurais próximos (sobretudo os abandonados).

A Tabela 4c mostra a mudança em fontes de renda domiciliar entre 1990 e 1999. Para todas as fontes, exceto a renda gerada fora do lote e da extração de madeira, a percentagem de renda domiciliar declina entre 1990 e 1999, com as quedas mais expressivas verificadas para os domicílios mais pobres (e com lotes menores). Tais resultados podem indicar maior vulnerabilidade às mudanças nas condições econômicas no período, com maior dependência do trabalho assalariado. Apenas os domicílios com lotes de $10 \mathrm{ha}$ a $20 \mathrm{ha}$ e acima de 60ha apresentaram aumento na parcela de renda gerada pelo cultivo de café.
Como resultado da combinação de fragmentação de lotes e declínio no preço de commodities, como café e carne bovina nos anos 1990, houve uma redução importante na proporção de renda gerada no lote através do gado (28\% em 1990 para 15\% em 1999) em todas as categorias de tamanho de lote, exceto para aqueles entre $30 \mathrm{ha} \mathrm{e}$ 40ha. A fonte de renda com maior aumento percentual é madeira, conforme mencionado acima, o que pode estar relacionado ao processo intenso de fragmentação de lotes e conversão de florestas em atividades agropecuárias. A renda gerada por atividades fora do lote torna-se, em 1999, a fonte mais importante de renda na região, com crescimento de $49 \%$ no período.

\section{3_ Desigualdade de renda e de terra}

Houve aumento ou diminuição da pobreza entre colonos migrantes do Norte da Amazônia equatoriana entre 1990 e 1999? Os domicílios rurais se encontravam em melhor situação em termos de tamanho dos lotes e de renda? Essas eram as duas questões principais antes $\mathrm{da}$ análise efetuada neste artigo, e as respostas diferem dependendo da medida utilizada. Apesar de a renda não ser uma medida completa de bem-estar econômico, a maioria das análises de pobreza e desigualdade no mundo é baseada em renda 
Tabela 4c_ Mudança percentual na renda média domiciliar rural e distribuição percentual por tamanho de lote - Norte da Amazônia equatoriana, 1990 a 1999

\begin{tabular}{|c|c|c|c|c|c|c|c|}
\hline $\begin{array}{c}\text { Tamanho } \\
\text { do Lote (ha) }\end{array}$ & $\begin{array}{c}\text { Renda } \\
\text { Domiciliar Média }\end{array}$ & $\begin{array}{c}\text { Número de } \\
\text { Domicílios Rurais }\end{array}$ & Café & Outros Cultivos $^{(a)}$ & Gado & Madeira & Fora do Lote \\
\hline $0-2$ & $-42,5$ & 375,0 & $-89,7$ & $-93,8$ & $-85,84$ & $-100,00$ & 252,90 \\
\hline $2-5$ & 34,2 & 884,6 & $-74,8$ & $-52,5$ & $-48,36$ & 16482,03 & 119,02 \\
\hline $5-10$ & 157,7 & 722,2 & $-4,3$ & $-58,2$ & 101,30 & - & 730,54 \\
\hline $10-20$ & 35,9 & 169,6 & 68,1 & $-20,7$ & $-22,95$ & 1713,47 & 695,63 \\
\hline $20-30$ & 32,9 & 81,6 & $-39,8$ & $-4,3$ & $-55,76$ & 1587,69 & 98,90 \\
\hline $30-40$ & $-15,5$ & 3,8 & $-41,2$ & $-28,2$ & 7,65 & 433,91 & 4561,28 \\
\hline $40-50$ & $-2,5$ & $-12,0$ & $-37,0$ & $-58,9$ & $-13,07$ & 1339,81 & 1171,28 \\
\hline $50-60$ & $-5,4$ & $-35,8$ & $-54,4$ & $-19,4$ & $-9,60$ & 394,64 & 158,64 \\
\hline $60-90$ & 66,2 & 50,0 & 8,0 & $-40,0$ & $-0,14$ & 1830,64 & 242,30 \\
\hline Mais de 90 & $-59,7$ & $-55,6$ & 22,1 & $-41,4$ & $-91,57$ & 59,84 & $-16,30$ \\
\hline Total & $-21,1$ & 58,2 & $-47,5$ & $-43,3$ & $-56,74$ & 1221,13 & 485,44 \\
\hline
\end{tabular}

(a) Inclui renda de todos os cultivos anuais, semianuais e perenes, além de café,

Fonte: Elaboração própria a partir de pesquisa domiciliar longitudinal (anos de 1990 e 1999)

realizada pelo Carolina Population Center, University of North Carolina at Chapel Hill (CPC/UNC).

(Robeyns, 2005). Dessa forma, este artigo utiliza as Curvas de Lorenz e os Coeficientes de Gini para tamanho do lote e renda domiciliar para examinar mudanças entre 1990 e 1999. A análise considerou domicílios rurais classificados nas mesmas dez categorias em 1990 e 1999, sendo utilizados os totais de renda gerada no lote e fora do lote. Em função do processo de fragmentação de lotes, o número total de domicílios rurais aumentou de 418 em 1990 para 658 em 1999.

Para computar o Coeficiente de Gini de desigualdade de renda, a percentagem de domićlios rurais por categoria de renda foi pareada à percentagem acumulada de domicílios. Os resultados mostram que o Coeficiente de Gini $(G)$ permanece praticamente inalterado entre $1990(0,554)$ e 1999 $(0,551)$. As Curvas de Lorenz, correspondentes aos Coeficientes de Gini estimados, mostram alguns aspectos adicionais, como a existência de um leve aumento, no tempo, da percentagem de domicilios rurais muito pobres, assim como de alguns poucos domicílios mais ricos, apesar de, no geral, isso não representar mudança na desigualdade. 
Figura 2a_ Curva de Lorenz e Coeficientes de Gini demonstrando a distribuição de terra no Norte da Amazônia equatoriana - 1990 e 1999

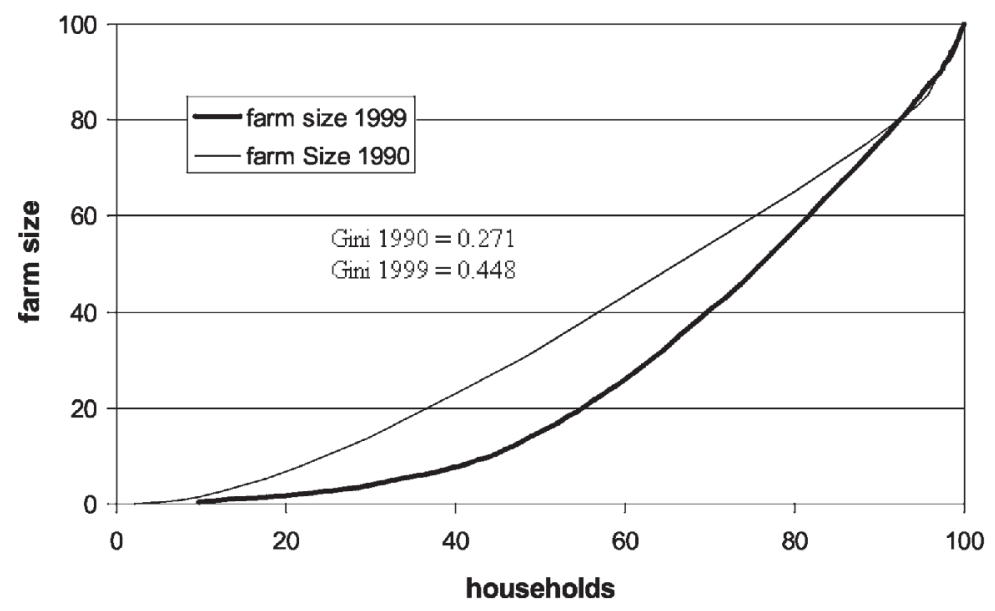

Fonte: Elaboração própria a partir de pesquisa domiciliar longitudinal (anos de 1990 e 1999) realizada pelo Carolina Population Center, University of North Carolina at Chapel Hill (CPC/UNC).

Figura 2b_ Curva de Lorenz e Coeficientes de Gini demonstrando a distribuição de renda no Norte da Amazônia equatoriana - 1990 e 1999

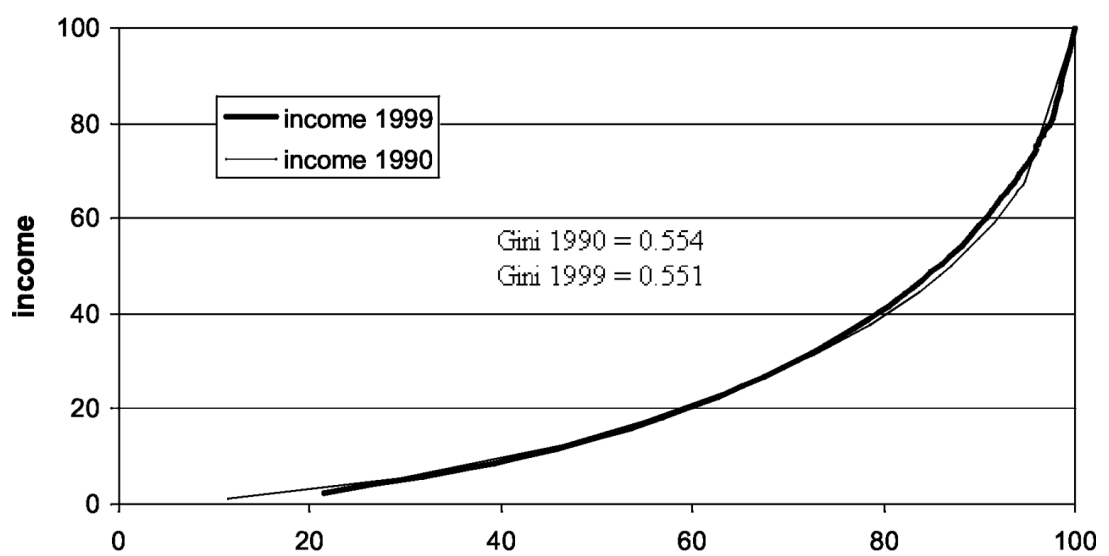

Fonte: Elaboração própria a partir de pesquisa domiciliar longitudinal (anos de 1990 e 1999) realizada pelo Carolina Population Center, University of North Carolina at Chapel Hill (CPC/UNC). 
Os dados demonstram que a proporção de domicílios muito pobres cresceu no período, dado o intenso processo de fragmentação de lotes, que levou a um aumento substancial no Coeficiente de Gini de distribuição de terra de 0,271 em 1990 para 0,448 em 1999. Tal aumento em um período relativamente curto é surpreendente e normalmente levaria a um aumento significativo no Coeficiente de Gini de desigualdade de distribuição de renda. Contudo, tal resultado é justificado se considerarmos os componentes principais da renda domiciliar nos dois anos em análise. Apesar de as fontes de renda geradas constituírem a maioria das rendas dos domicílios em 1990 e 1999, a sua participação cai substancialmente de $74 \%$ em 1990 para $57 \%$ em 1999, decrescendo para cerca da metade em termos monetários. Por outro lado, a renda gerada fora do lote aumenta de 17\% para 43\% em 1999. Assim, mais importante do que reduzir a desigualdade, a participação da renda gerada fora do lote cresceu de cerca de $20 \%$ para os poucos domicílios com menos de 10 ha em 1990 para mais de $60 \%$ em 1999. Dessa forma, a renda gerada fora do lote rural - predominantemente por meio do trabalho assalariado - suaviza o aumento dramático na desigualdade de distribuição de terra, de forma a manter praticamente inalterada a desigualdade de renda. Nota-se ainda, com base na Tabela $2 \mathrm{~b}$, que a quantidade absoluta de renda gerada fora do lote declarada pelos domicílios com pequenos lotes em 1999 difere muito pouco do declarado por domićlios com lotes médios ou grandes, em contraste com a renda gerada no lote.

\section{6_Conclusões e implicações do estudo}

Este artigo utiliza dados longitudinais raros para áreas de fronteira em países em desenvolvimento - para investigar as características da renda domiciliar rural de colonos migrantes no Norte da Amazônia equatoriana, assim como características populacionais, tamanho da terra e uso da terra, entre 1990 e 1999. O artigo mostra que é possível, e desejável, coletar informações detalhadas para mensurar a renda auferida em áreas de fronteira como a Amazônia e, dessa forma, gerar informações fundamentais para a implementação de políticas direcionadas à população de colonos e habitantes da floresta. Entretanto, e em função das próprias especificidades do estudo, há algumas limitações nos dados coletados, como a subestimação de alguns itens da produção no lote, em função tanto de erros de memória do informante quanto de subestimação deliberada (como no caso da renda produzida pela extração de madeira). 
Os resultados mostram, de forma geral, uma queda na renda em domicílios de colonos, em função de fatores exógenos - como o declínio no preço internacional de café e de carne bovina nos anos 1990 - e também, e mais importante, de fatores endógenos relacionados à fragmentação de lotes rurais e ciclos de vida das famílias relacionados à formação de outros domicílios. Assim, as mudanças no nível de renda entre 1990 e 1999 são afetadas pelas possibilidades limitadas de extensividade (extensificação) na área em estudo na Amazônia equatoriana, à medida que a fronteira se torna cada vez mais fechada como consequência da titulação de terras indígenas e criação de reservas florestais na área em estudo. Essa situação contrasta com a Amazônia brasileira, onde a fronteira ainda é considerada aberta tendo em vista a possibilidade de ocupação e produção em diversas partes e onde as pressões populacionais são menores em função do menor nível de fecundidade da população e do arrefecimento da migração para a fronteira. Notase, por exemplo, que o efeito da fecundidade alta no Equador no passado, principalmente nos anos 1980, pressiona a oferta de terras, levando a um processo intenso de fragmentação, especialmente para os filhos dos colonos que atingem a idade adulta $\mathrm{e}$ passam a demandar terras, ou mesmo a venda de parte das terras para novos migrantes que continuavam a chegar à região durante os anos 1990. Nessa época, houve ainda aumento significativo na parcela de renda domiciliar gerada fora do lote, principalmente por meio do trabalho assalariado, contribuindo para uma diversificação ainda maior do portfólio domiciliar, minimizando riscos à subsistência e diversificando fontes de renda.

Outra consequência direta da queda da fecundidade e da emigração de indivíduos de domicilios dos colonos originais (por exemplo, um filho que atinge idade adulta casa-se e constitui novo domicílio) é o declínio no tamanho médio dos domicilios entre 1990 e 1999. Essa queda virtualmente eliminou o declínio na renda per capta dos domicílios, gerando uma espécie de "dividendo demográfico". No entanto, apesar do dividendo e da maior diversificação nas fontes de renda (principalmente mediante o trabalho assalariado fora do lote), os domicílios de colonos têm, em geral, experimentado aumento na situação de pobreza.

O grande aumento na desigualdade de terra, com o Coeficiente de Gini subindo de 0,27 para 0,45 ou em dois terços em menos de uma década, não está relacionado a um processo de consolidação de terras padrão típico da Amazônia brasileira (ver, por exemplo, Schmink e Wood, 1992), mas 
sim à fragmentação dos lotes rurais. Tem-se, então, não apenas um processo de invasão de terras por novos migrantes que levam a um aumento na desigualdade, mas também o efeito inercial da alta fecundidade no passado. Este último não é usualmente mencionado como um fator importante determinando a dinâmica de uso da terra em áreas de fronteira, apesar de sua importância em muitas áreas do mundo, além da área em estudo neste artigo.

Um resultado intrigante neste estudo é o grande aumento na desigualdade de terras e, ao mesmo tempo, a ausência de mudança na medida de desigualdade de renda. Tal resultado é explicado por dois fatores principais. Em primeiro lugar, observa-se durante a década um declínio na renda produzida no lote em função da queda no preço de mercado dos principais produtos agropecuários, reduzindo até o valor da terra como fator de produção. $\mathrm{O}$ segundo fator é a crescente oferta de trabalho assalariado fora dos lotes rurais, o que contribuiu para amenizar os impactos da distribuição de terras ao colocar domicílios com pouca terra em condições mais iguais na geração de renda em relação a domicílios com maior oferta de terras.

$\mathrm{O}$ foco das pesquisas em fronteiras de florestas tropicais, como a Amazônia, tem sido majoritariamente sobre as conse- quências ecológicas da destruição da floresta - para a biodiversidade, as mudanças climáticas e a hidrologia. As políticas públicas têm, dessa forma, focado na preservação das florestas, como manter as pessoas fora das florestas (Terborgh, 2004) ou como engajá-las em formas de manejo menos destrutivo das florestas. O bem-estar das populações que residem nessas áreas tem sido quase sempre ignorado, apesar de ser absolutamente irrealista pensar em preservação da floresta sem confrontar o elemento humano e como desenvolver políticas que preservem o que resta das florestas tropicais e ao mesmo tempo assegure o bem-estar das populações.

Várias políticas podem ser consideradas para aliviar a pobreza e atingir um padrão de desenvolvimento mais sustentável. Embora políticas emergenciais no Equador, como a extensão de programas assistencialistas para a Amazônia, possam aliviar a pobreza no curto prazo, políticas de longo prazo são fundamentais, como a extensão de programas de planejamento familiar, os quais são virtualmente ausentes na região apesar da ainda alta fecundidade das mulheres e o fato de dois terços delas não quererem mais filhos (conforme resultados da pesquisa realizada em 1999). Ainda que o declínio na fecundidade nos anos 1990 tenha auxiliado as famílias a lidar com a que- 
da no preço da produção agrícola, o nível ainda é alto, e declínios adicionais demandam a melhor provisão de serviços públicos de saúde e educação. Outra política necessária é aquela relacionada à extensão e à assistência agrícola, especialmente as que redirecionem cultivos de café e criação de gado para outras práticas mais lucrativas e que, ao mesmo tempo, representem maior possibilidade de equilibrio com a floresta. Por fim, a continuação do processo de urbanização (e a criação de oportunidades de trabalho assalariado) é desejável e tem ocorrido espontaneamente, apesar de a expansão da infraestrutura pelo setor público necessitar de melhor planejamento de forma a melhor contribuir para a expansão sustentável das cidades e a criação de polos de crescimento. 


\section{7_Referências bibliográficas}

ADGER, W. N.; Brown, K. Land use and the causes of global warming. Wiley \& Sons, 1994.

ALMEIDA, A. L. O. The colonization of the Amazon. Austin, Texas: University of Texas Press, 1992.

ARAMBURU, C. Expansion of the agrarian and demographic frontier in the Peruvian Selva. In: Contested frontiers in Amazonia. SCHMINK, M.; WOOD, C. H. (Ed.). Gainesville, Fl.: Florida University Press, 1984.

ATKINSON, A. Measurement of inequality. Journal of Economic Theory, v. 1, p. 244-263, 1970.

BARBIERI, A. F. People, land, and context: multi-scale dimensions of population mobility in the Ecuadorian Amazon. Ph.D.

Dissertation, City and Regional Planning. Chapel Hill: University of North Carolina, 2005.

BARBIERI, A. F.; BILSBORROW, R. E.; PAN, W. K. Farm household lifecycles and land use in the Ecuadorian Amazon. Population and Environment, v. 27, n. 1, p. $1-27,2005$ a.
BARBIERI, A. F.; SAWYER, D. O.; SOARES, E. B. S. Population and land use effects on malaria prevalence in the Southern Brazilian Amazon. Human Ecology, v. 33, n. 6, 2005b.

BILSBORROW, R. Migration, population change, and the rural environment. Environment Change \& Security Project Report, Summer, v. 8, p. 69-94, 2002.

BILSBORROW, R. E., BARBIERI, A. F. et al. Changes in population and land use over time in the Ecuadorian Amazon. Acta Amarônica, v. 34, n. 4, p. 635-647, 2004.

BILSBORROW, R. E.; HUGO, G. H.; ZLOTNIK, E H. International migration statistics. Geneva, International Labour Organization, 1997.

BISHOP, J. A.; FORMBY, J. P.; THISTLE, P. D. Changing

American earnings distributions: One-half century of experience. In: SLOTTJE, D. J.; BALDEV, R. (Eds.). Income Inequality, poverty, and economic welfare. New York: Physica-Verl, 1998.
BROMLEY, R. The colonization of humid tropical areas in Ecuador. Singapore Journal of Tropical Geography, v. 2, n. 1, p. 15-26, 1981

BROWN, L. Facing food insecurity, toward a sustainable society. The state of the world 1994, edited by L. BROWN, Chapter 10. New York, NY: W.W. Norton \& Co., 1994.

CARR, D. L. Proximate population factors and deforestation in tropical agricultural frontiers. Population and Environment, v. 25, n. 6 , p. 585-612, 2004

DALE, Virginia H. The relationship between land-use change and climate change. Ecological Applications, v. 7, n. 3, p. 753-769, 1997.

FEARNSIDE, P. M. Amazonian deforestation and global warming: carbon stocks in vegetation replacing Brazil's Amazon forest. Forest Ecology and Management, v. 80, p. 21-34, 1996.

FOOD AND AGRICULTURAL ORGANIZATION. Forest Resources Assessment. Rome. Also at www.fao.org, 2005.
HENRIQUES, M. H. The colonization experience in Brazil. In: OBERAI, A. S. (Ed.). Land settlement policies and population redistribution in developing countries: achievements, problems and prospects. New York: Praeger, 1988.

HIRAOKA, M.; YAMAMOTO, S. Agricultural development in the Upper Amazon of Ecuador. Geographical Review, v. 70 , n. 4 p. 423-445, 1980

INEC. V Censo de Población y IV de Vivienda; Resultados Definitivos. Quito: INEC (Instituto Nacional de Estadísticas y Censos), 1992.

INEC. VI Censo de Población y V Censo de Vivienda, 2001. Quito: INEC, 2001.

KOLM, S. C. The optimal production of social justice. In: MARGOLIS J.; GUITTON, H. (Eds.). Public Economics. London: Macmillan, 1969.

LAURANCE, W. F.;

WILLIAMSON, G. B. Positive

feedbacks among forest fragmentation, drought, and climate change in the Amazon. Conservation Biology, v. 15, n. 6 , p. 1529, 2001. 
LOKER, W. The human ecology of cattle raising in the Peruvian Amazon: the view from the farm. Human Organization, v. 52, n. 1 , p. 14-24, 1993.

MARQUETTE, C. M. Land use patterns among small farm settlers in the Northeastern Ecuadorian Amazon. Human Ecology, v. 26, n. 4, p. 573-598, 1998.

MURPHY, L. Making a living in the rainforest: factors affecting economic status in the Ecuadorian Amazon. Ph.D. Dissertation, Department of City and Regional Planning. Chapel Hill, NC, University of North Carolina at Chapel Hill, 1998.

MURPHY, L.; BILSBORROW, R.; PICHON, E. F. Poverty and prosperity among migrant settlers in the Amazon Rainforest Frontier of Ecuador. Journal of Development Studies, v. 34, n. 2, p. 35-66, 1997.

MYERS, N. Loss of biological diversity and its impact on agriculture and food production. In: PIMENTEL, D.; HALL, C. (Eds.). Food and Natural Resources. San Diego: Academic Press, p. 50-69, 1989.

MYERS, N. Population: some overlooked issues. The Environmentalist, v. 18, n. 3, p. 135-138, 1998.

MYERS, N.; MITTERMEIER R. A. et al. Biodiversity hotspots for conservation priorities. Nature, v. 403 , p. $853-858,2000$
O' BRIEN, K. Deforestation and climate change in the Selva Lacandona of Chiapas, Mexico. Ph.D.

Dissertation. Department of Geography. College Park, Penn. State University, 1995

PAINTER, M. Unequal exchange: The dynamics of settler impoverishment and environmental destruction in Lowland Bolivia. In: LITTLE, P.; HOROWITZ, M. (Ed.). Lands at risk in the third world: local-level perspectives. Boulder, CO: Westview Press, 1987.

PANAYOTOU, T.; S

SUNGSUWAN. An econometric analysis of the cause of tropical deforestation: the case of Northeast Thailand. In: BROWN, K.; PEARCE, D. W. (Ed.). The causes of tropical deforestation. London: UCL Press, p. 192-210, 1994.

PERZ, S. G. Household demography and land use allocation among small farms in the Brazilian Amazon. Human Ecology Review, v. 9, n. 2, p. 1-16, 2002.

PICHÓN, F. Settler households and land-use patterns in the Amazon Frontier: farm-level evidence from Ecuador. World Development, v. 25 , n. 1 p. 67-91, 1997.
PICHÓN, F.; BILSBORROW, R.

E. Land-use systems, deforestation and associated demographic factors in the humid tropics: Farm-level evidence from Ecuador. In: BILSBORROW, R.; HOGAN, D. (Ed.). Population and deforestation in the humid tropics. Belgium: IUSSP, 1999.

ROBEYNS, Ingrid. Assessing global poverty and inequality: income, resources, and capabilities. Metaphilosophy, v. 36, n. $1 / 2,2005$

ROSERO-BIXBY, L.; PALLONI, A. Population and deforestation in Costa Rica.

Population and Environment, v. 20, n. 2 , p. $149-185,1998$.

RUDEL, T.; ROPER, J. The paths to rain forest destruction: cross-national patterns of tropical deforestation, 1975-1990.

World Development, v. 25, n. 1 , p. 53-65, 1997.

RUDEL, T.; HOROWITZ, B. (1993). Tropical deforestation: Small farmers and land clearing in the Ecuadorian Amazon. New York, Columbia University Press.

SCHMINK, M.; WOOD. C. H. Constested frontiers in Amazonia. New York, Columbia: University Press, 1992.

SHUKLA, J. C.; NOBRE, C.; SELLERS, P. Amazon deforestation and climate change. Science, v. 247, p. 1322-1325, 1990.

SIMON, H. A. Administrative Behavior. New York, Free Press, 1976.
SINGER, B.; SAWYER, D. O. Perceived malaria illness reports in mobile populations. Health Policy and Planning, v. 7, n. 1, 1992.

SINGH, I.; SQUIRE, L.;

STRAUSS, J. The basic model: theory, empirical results, and policy conclusions. In: SINGH, I.; SQUIRE, L. (Ed.). Agricultural Household Models, Johns Hopkins University Press, Baltimore, MD 1986. p. 17-47.

SLOTTJE, D. J.; BALDEV, R. (Eds.). Income inequality, poverty, and economic welfare. Heidelberg and New York: Physica-Verl, 1998.

STRAUSS, J. The theory and comparative statics of agricultural household models: a general approach. In: SINGH, I.; SQUIRE, L. (Ed.). Agricultural Housebold Models, Johns Hopkins University Press, Baltimore, MD, 1986.

TERBOGH, J. Requiem for nature. Island Press, 2004

THAPA, K.; BILSBORROW, R. E.; MURPHY, L. Deforestation and women in the Ecuadorian Amaron: linkages between environmental degradation and women's agricultural activities. San Francisco, 1995. (Paper presented at Annual Meeting of Population of America Association).

THORNER, D.; KERBLAY, B. et al. A. V. Chayanov on the Theory of Peasant Economy. Madison, University of Wisconsin Press. 1986. 
TINKER, P. B.; INGRAM, J.; STRUWE, S. Effects of slash-and-burn agriculture and deforestation on climate change. Agriculture, Ecosystems \&

Environment, v. 58, p. 13-22, June 1996

UQUILLAS, J. Colonization and spontaneous settlement in the Ecuadorian Amazon. In: SCHMINK, M.; WOOD, C. (Ed.). Contested Frontiers in Amaronia. Gainesville, FL, University of Florida Press, 1984.

WALKER, R.; HOMMA, A. K. O. Land use and land cover dynamics in the Brazilian Amazon: an overview. Ecological Economics, v. 18, n. 1, p. 67-80, 1996.

WALKER, R.; PERZ, S. et al. Land use and land cover change in forest frontiers: the Role of household life cycles. International Regional Science Review, v. 25, n. 2, p. 169-199, 2002.

WILSON, E. O. The diversity of life. New York: W. W. Norton \& Co, 1992

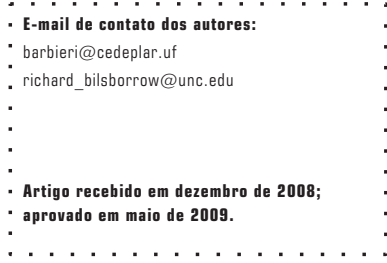

